\section{Native Bees, Honeybees, and Pollination in Oregon Cranberries}

\author{
Melissa Broussard $\mathbf{1}$, Sujaya Rao, and William P. Stephen \\ Department of Crop and Soil Sciences, Oregon State University, 3017 ALS, \\ Corvallis, OR 97331
}

\section{Linda White \\ Department of Horticulture, Oregon State University Extension, 631 Alder Street, Myrtle Point, OR 97458}

Additional index words. Pacific Northwest, Bombus vosnesenskii, Apis mellifera, Vaccinium macrocarpon

\begin{abstract}
Cultivated cranberry (Vaccinium macrocarpon Aiton) relies on insect pollination for berry production. Honeybees (Apis mellifera L.) have historically provided this service, but their recent decline has underscored the need for additional pollinators. The objective of this study was to determine the richness and abundance of native bees in the cranberry-growing area of southern coastal Oregon and compare foraging behaviors of honeybees and native bees. In a 2-year study, we collected over 27 native bee species in traps set out during and after bloom (mid-May to mid-June). During 67 2-min observations, honeybees (68.1\%) and three species of bumble bees (Bombus spp.; $31.6 \%$ ) comprised $99.7 \%$ of foragers. The dominant bumble bee was Bombus vosnesenskii Radoszkowski $(56.0 \%)$. Multivariate regression of temperature and wind speed data indicated that both were significantly predictive of honeybee and bumble bee foragers $(P<0.001)$. The interquartile range for foraging was 18.3 to $22.2^{\circ} \mathrm{C}$ for bumble bees and 21.1 to $26.7{ }^{\circ} \mathrm{C}$ for honeybees. Over $75 \%$ of honeybees were seen foraging above the average observed temperature $\left(19.5^{\circ} \mathrm{C}\right)$. Bumble bee pollen loads had a greater dry mass $(6.8 \pm 12.9 \mathrm{mg})$ than those of honeybees $(2.0 \pm 3.6 \mathrm{mg} ; \boldsymbol{P}<0.001)$, and the latter were observed collecting nectar but no pollen more often (during $37.2 \%$ of visits) than bumble bees (11.3\% of visits). Based on our results, bumble bees in general, and $B$. vosnesenskii in particular, may be providing significant pollination services for Oregon cranberry farms. However, to maintain current native bumble bee populations, conservation efforts are recommended.
\end{abstract}

The domesticated cranberry is a low, perennial woody vine native to northeastern North America (Eck, 1986). Fruit set and fruit size are maximized when eight or more pollen grains are transferred to the stigma of the flower; if fewer than four viable grains reach the stigma, fruits are small, deformed, or altogether absent (Cane and Schiffhauer, 2003). As a result of limited self-compatibility, for optimal fruit set, cranberry requires outcrossing by insect pollinators (Sarracino and Vorsa, 1991). In North America, Apis mellifera, the European honeybee, is used extensively to provide pollination services for cranberry (Evans and Spivak, 2006; Ratti et al., 2008; personal observation). However, cranberry flowers have poricidal anthers

Received for publication 20 Dec. 2010. Accepted for publication 15 Apr. 2011

The study was funded by a URISC scholarship to Melissa Broussard and by funding to Sujaya Rao from the Oregon Cranberry Growers' Association and WSARE.

We thank Richard Halse for plant identification, Kim Skyrm for acetolysis procedures, and growers for permitting the study in their cranberry beds. Sarah Maxfield-Taylor and Kim Skyrm reviewed an earlier version.

${ }^{1}$ To whom reprint requests should be addressed; e-mailmckennem@onid.orst.edu. whose pollen is best accessed by buzz pollination (Buchmann, 1983; Free, 1993). Because honeybees do not buzz-pollinate, they are considered to be less effective at removing pollen from this type of anther (Cane et al., 1996; Cane and Schiffhauer, 2001; King and Buchmann, 2003; MacKenzie, 1994), although some pollen transfer may still occur while foraging for pollen and/or nectar. Additionally, the number of available hives has decreased with recent threats to honeybee health such as Colony Collapse Disorder. As a result of these factors, alternative pollinators are needed for pollination services in cranberries.

Cranberry pollination research in North America has largely been conducted in the Great Lakes and New England areas and has focused on the use of commercially available bee species: honeybees, managed bumble bees (Bombus spp.; Cane and Schiffhauer, 2003; Evans and Spivak, 2006; Stubbs and Drummond, 1997), leafcutter bees (Megachile spp; Cane et al., 1996; Cane and Schiffhauer, 2003; MacKenzie and Javorek, 1997; Stubbs and Drummond, 1997), and mason bees (Osmia spp.; Cane and Schiffhauer, 2003; Stubbs and Drummond, 1997). In these studies, bumble bees proved to be effective pollinators of cranberries, depositing, on average, over 60 pollen grains per visit, resulting in a twofold increase in berry mass, compared with pollination by honeybees, which deposited only 10 pollen grains per visit (Cane and Schiffhauer, 2003). In addition, honeybees are reported to be more likely than bumble bees to collect nectar and not pollen (MacKenzie, 1994). Although this behavior results in stigmatic contact, pollen foraging yields $63 \%$ more berries than nectar foraging (Cane and Schiffhauer, 2001). For these reasons, previous studies have concluded that bumble bees are superior pollinators of cranberry (Cane and Schiffhauer, 2003; Macfarlane, 1995; Ratti et al., 2008), particularly short-tongued bumble bees (Macfarlane et al., 1994; Macfarlane and Patten, 1997). However, others question if populations are sufficient to provide adequate pollination (Evans and Spivak, 2006; Filmer and Doehlert, 1959; Free, 1993). In contrast to the Midwest and the East, little research has been done on cranberry production systems in the west, where $\approx 16 \%$ of the cranberries in North America are produced (BC Cranberry Growers Association, 2007; USDA, 2009a). Of these, Oregon produces $4 \%$, worth $\$ 36.6$ million (USDA, 2009b).

Cranberries bloom from mid-May to mid-July in Oregon, during which time cool, overcast, and windy conditions prevail. These conditions do not favor foraging by honeybees and can dramatically reduce their pollination efficacy (Burrill and Dietz, 1981; Percival, 1947). In contrast, native bees, adapted to coastal conditions, have the potential to be superior pollinators. There is a great diversity of bees native to Oregon, but little data exist pertaining to which species are present in cranberry-producing areas and which species are associated with cranberry bloom.

The objectives of this study were to: 1) estimate native bee richness and abundance in the cranberry-growing region of Oregon; 2) correlate bee foraging behaviors with the abiotic factors of temperature and wind; and 3 ) compare pollen loads from honeybees and native bees foraging on cranberry flowers.

\section{Materials and Methods}

Study sites. Four farms were selected for this study (Sites 1-4, Fig. 1) with total cranberry acreage ranging from 4.5 to 65.0 ha. Sites were separated by 4.2 to $9.8 \mathrm{~km}$. All four farms rented 0.5 to 1.0 honeybee hives per hectare of crop.

Estimation of native bee richness and abundance. Fluorescent blue vane traps (SpringStar LLC, Woodinville, WA), which have been found to be effective for native bee monitoring studies (Stephen and Rao, 2005), were used to sample bees. Each trap consisted of a clear plastic collection jar $(15 \mathrm{~cm}$ diameter $\times 15 \mathrm{~cm}$ high) with a funnel cap and two cross-vanes $(24 \mathrm{~cm}$ tall $\times 13 \mathrm{~cm}$ wide) made of fluorescent blue polypropylene. Two traps were hung at each site $10 \mathrm{~cm}$ above the ground for $12 \mathrm{~h}$; traps were set up between 0530 and $0700 \mathrm{HR}$ and taken down between 1730 and 1900 HR. Sampling occurred once per week during bloom and once every other week before and after cranberry bloom in 
2008 and 2009. Bees caught in the traps were pinned and identified.

Correlation of bee foraging behavior with abiotic factors. Two-min counts of all foraging bees were taken along a 1-m-wide transect at Site 4. Apis and Bombus were visually identified to species, except Bombus vosnesenskii and B. caliginous, which could not be differentiated visually. Other bees were identified to genus. Before every count, wind speed and temperature were measured with an anemometer and recorded.

Comparison of pollen loads from foraging bees. Honeybees and bumble bees were collected for analysis of pollen loads. This study was conducted at Site 4 on the same days that the blue vane traps were set up. Bees were hand-collected by placing a vial over a flower. To the extent possible, four honeybees and four bumble bees were collected over a 30-min period during which temperature and wind speed were also recorded. Specimens were collected every $2 \mathrm{~h}$ between 0800 and $1400 \mathrm{HR}$. Bees were immediately chilled, identified, their pollen loads removed with a paintbrush, and then released. The labeled pollen was chilled in the field and frozen subsequently until processed for identification.

Pollen loads were dried and weighed. If pollen was present, but too light to be weighed (less than $0.1 \mathrm{mg}$ ), its weight was recorded as $0.05 \mathrm{mg}$. Dried pollen was then identified after acetolysis using procedures modified from those described by Erdtman (1952). Pollen was stained with $0.01 \%$ safranin $\mathrm{O}$ and mounted on slides with silicone oil. To facilitate pollen

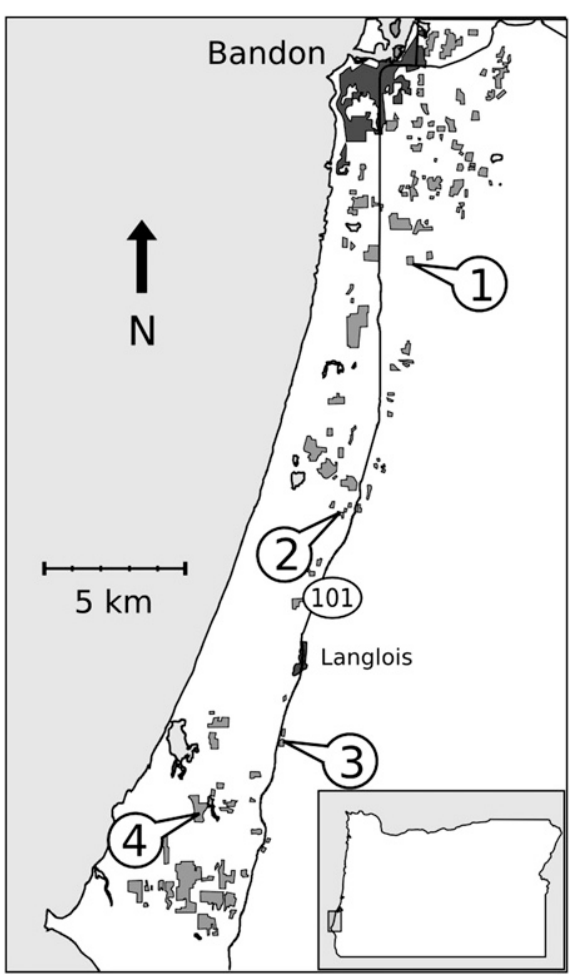

Fig. 1. Map of research sites along the southern Oregon coast. Numbers correspond to sites listed in the text. Dark gray indicates urban areas; medium gray indicates cranberry beds. identification, anthers were collected from flowers observed blooming around cranberry beds at all four sites and the pollen processed as described previously for creation of a reference pollen collection. From each load, 200 pollen grains were identified. Because ericaceous pollen grains are similar in morphology but differ in size, size was used to separate cranberry pollen ( 12.5 to $15.0 \mu \mathrm{m}$ across) from other ericaceous pollen (10.0 to $12.0 \mu \mathrm{m}, 20.0$ to $27.5 \mu \mathrm{m})$.

Data analysis. Data on the numbers of foraging honeybees and bumble bees were analyzed using R (R Development Core Team, 2010) to create binomial logistic regression models for bee foraging behavior. Single-variable regressions were used to determine the correlation between wind speed and foragers and temperature and foragers. A multivariate regression model was created to examine the relationship among wind, temperature, and foragers together. Pollen load weights of bumble bees and honeybees were compared using a Wilcoxon rank-sum test. All tests were analyzed with $\alpha=0.05$.

\section{Results}

Estimation of native bee richness and abundance. Over two growing seasons, 1330 bees were collected, representing five families, 13 genera, and over 27 native species in addition to $A$. mellifera (Table 1). Of these, bumble bees (Bombus spp.), metallic sweat bees (Agapostemon spp.), and small sweat bees (Lasioglossum spp.) were recorded in higher abundance than honeybees. Bumble bees comprised $25.1 \%$ of all bees captured with five species represented (in order of abundance): $B$. vosnesenskii, $B$. mixtus Cresson, $B$. melanopygus Nylander, B. caliginosus Frison, and $B$. californicus Smith. The most abundant was $B$. vosnesenskii, which constituted $42.4 \%$ of all trapped bumble bees. Two species of Agapostemon were trapped of which $A$. texanus Cresson $(24.6 \%$ of all bees and $98.5 \%$ of all Agapostemon captured) was more abundant than A. virescens (Fabricius).

Correlation of bee foraging behavior with abiotic factors. During 67 2-min counts made of bees foraging in cranberry beds over the 2-year study, honeybees $(68.1 \%)$ and bumble bees $(31.6 \%)$ were the most abundant. The average number of honeybees observed was $4.88 \pm 0.60$ and the average number of bumble bees was $0.40 \pm 0.25$. Of the 96 bumble bees observed, the majority of foragers were workers from the $B$. vosnesenskii/ $B$. caliginosus complex $(70.8 \%)$ followed by $B$. mixtus $(22.9 \%)$ and $B$. melanopygus $(6.3 \%)$. A single halictid bee was observed representing $0.3 \%$ of the total foragers.

Temperature was highly correlated with both honeybee and bumble bee foragers $(P<$ 0.001 ; Fig. 2). The interquartile range of bumble bee foraging was 18.3 to $22.2{ }^{\circ} \mathrm{C}$, whereas that of honeybees was 21.1 to $26.7{ }^{\circ} \mathrm{C}$. There was no correlation between the number of foragers and either the minimum $(P=0.067)$ or maximum $(P=0.104)$ wind speed.

When considered together in a multivariate analysis, both temperature $(P<0.001)$ and wind speed $(P=0.001)$ were significant predictors of bee foragers (Table 2). The average temperature observed during the visual counts was $19.5^{\circ} \mathrm{C}$. The highest numbers of bumble bees were observed foraging between 18 and $22{ }^{\circ} \mathrm{C}$, whereas the highest numbers of honeybees were recorded when temperatures exceeded $24{ }^{\circ} \mathrm{C}$, which occurred during less than $20 \%$ of observations over the study period.

Comparison of pollen loads from foraging bees. Of the worker bees collected for pollen analysis, $62.8 \%$ of honeybees and $88.7 \%$ of

Table 1. Bees trapped in southwestern Oregon cranberry agroecosystems in 2008 and 2009.

\begin{tabular}{|c|c|c|c|c|c|c|}
\hline \multirow[b]{2}{*}{ Family } & \multirow[b]{2}{*}{ Species } & \multirow{2}{*}{$\begin{array}{l}\text { Number } \\
\text { collected }^{\mathrm{z}}\end{array}$} & \multicolumn{4}{|c|}{ Sites where present } \\
\hline & & & 1 & 2 & 3 & 4 \\
\hline Andrenidae & Andrena sp. & 10 & $\sqrt{ }$ & $\sqrt{ }$ & $\sqrt{ }$ & $\sqrt{ }$ \\
\hline \multirow[t]{10}{*}{ Apidae } & Apis mellifera $\mathrm{L}$. & 235 & $\sqrt{ }$ & $\sqrt{ }$ & $\sqrt{ }$ & $\sqrt{ }$ \\
\hline & Bombus californicus Smith & 4 & $\sqrt{ }$ & & $\sqrt{ }$ & \\
\hline & Bombus caliginosus (Frison) & 40 & $\sqrt{ }$ & $\sqrt{ }$ & & $\sqrt{ }$ \\
\hline & Bombus melanopygus Nylander ${ }^{\mathrm{y}}$ & 60 & $\sqrt{ }$ & $\sqrt{ }$ & & $\sqrt{ }$ \\
\hline & Bombus mixtus Cresson & 101 & $\sqrt{ }$ & $\sqrt{ }$ & & $\sqrt{ }$ \\
\hline & Bombus vosnesenskii Radozkowski & 151 & $\sqrt{ }$ & $\sqrt{ }$ & $\sqrt{ }$ & $\sqrt{ }$ \\
\hline & Ceratina sp. & 1 & & & $\sqrt{ }$ & \\
\hline & Melissodes spp. & $57(2)$ & $\sqrt{ }$ & $\sqrt{ }$ & $\sqrt{ }$ & $\sqrt{ }$ \\
\hline & Nomada sp. & 1 & $\sqrt{ }$ & & & \\
\hline & Synhalonia sp. & 4 & $\sqrt{ }$ & $\sqrt{ }$ & & $\sqrt{ }$ \\
\hline Colletidae & Colletes sp. & 3 & $\sqrt{ }$ & & & $\sqrt{ }$ \\
\hline \multirow[t]{9}{*}{ Halictidae } & Agapostemon texanus Cresson & 329 & $\sqrt{ }$ & $\sqrt{ }$ & $\sqrt{ }$ & $\sqrt{ }$ \\
\hline & Agapostemon virescens (Fabricius) & 5 & $\sqrt{ }$ & & $\sqrt{ }$ & $\sqrt{ }$ \\
\hline & Halictus rubicundus Christ & 28 & $\sqrt{ }$ & $\sqrt{ }$ & $\sqrt{ }$ & $\sqrt{ }$ \\
\hline & Halictus tripartitus Cockerell & 3 & $\sqrt{ }$ & $\sqrt{ }$ & & \\
\hline & Lasioglossum mellipes (Crawford) & 1 & & & & $\sqrt{ }$ \\
\hline & Lasioglossum olympiae (Cockerell) & 5 & $\sqrt{ }$ & $\sqrt{ }$ & & $\sqrt{ }$ \\
\hline & Lasioglossum pacificum (Cockerell) & 39 & $\sqrt{ }$ & $\sqrt{ }$ & $\sqrt{ }$ & $\sqrt{ }$ \\
\hline & Lasioglossum sisymbrii (Cockerell) & 1 & $\sqrt{ }$ & & & \\
\hline & Lasioglossum spp. & $239(6)$ & $\sqrt{ }$ & $\sqrt{ }$ & $\sqrt{ }$ & $\sqrt{ }$ \\
\hline \multirow[t]{2}{*}{ Megachilidae } & Megachile spp. & $16(2)$ & $\sqrt{ }$ & $\sqrt{ }$ & $\sqrt{ }$ & $\sqrt{ }$ \\
\hline & Osmia sp. & 2 & $\sqrt{ }$ & & & $\sqrt{ }$ \\
\hline
\end{tabular}

${ }^{\mathrm{z}}$ Numbers in parentheses indicate approximate number of species.

${ }^{\mathrm{y}}$ Including individuals with the black phenotype earlier referred to as $B$. edwardsii. 
bumble bees had pollen loads. Bees collected without pollen loads were observed foraging for nectar rather than pollen. Honeybee loads $(2.0 \pm 3.6 \mathrm{mg})$ were significantly smaller than bumble bee loads $(6.8 \pm 12.9 \mathrm{mg} ; P<0.001)$. On average, honeybee loads contained $89.4 \%$ cranberry pollen with the remainder comprised of one to three other pollen types, whereas bumble bee loads contained $82.0 \%$ cranberry pollen with one to five other pollen types. For both bee species, the most common non-cranberry pollen was from fabaceous plants $(7.1 \%$ of all pollen), whereas pollen from plants belonging to Asteraceae (2.4\%), Ranunculaceae (1.2\%), and Rhamnaceae $(0.9 \%)$ were also recorded. No statistical difference $(P=0.300)$ in pollen composition was observed between the two bee genera.

\section{Discussion}

This is the first study documenting the richness and abundance of native bees in the cranberry-growing region of Oregon. Although over 25 species were present in the cranberrygrowing region based on trapping data, five are likely to play a role in cranberry pollination based on visual observations of foragers during bloom: honeybees, $B$. vosnesenskii, $B$. mixtus, $B$. melanopygus, and B. caliginosus. Although $B$. caliginosus and B. vosnesenskii cannot be differentiated on the wing, trap catches may be used to inform visual observations. Given that $B$. vosnesenskii was 3.8 times as common as $B$. caliginosus, we speculate that $B$. vosnesenskii accounted for $56.0 \%$ of foraging Bombus, whereas $B$. caliginosus accounted for only $14.8 \%$. Although species belonging to 11 other genera were present in the traps, they were not

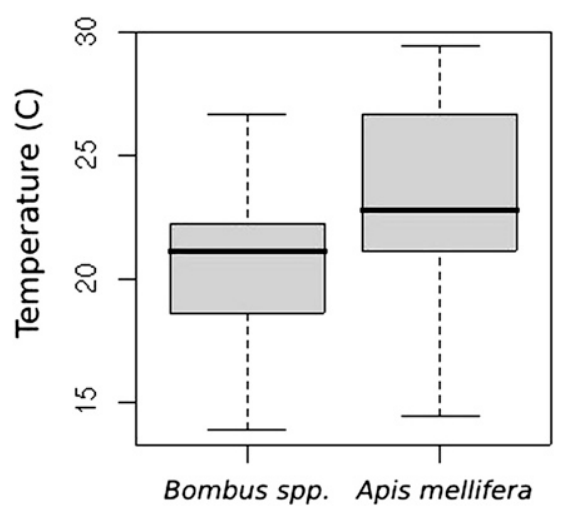

Fig. 2. Temperatures at which bumble bees $(\mathrm{n}=$ 96), and honeybees $(n=207)$ were observed foraging on cranberry bloom. The distributions differ significantly $(P<0.001)$ for the two species. observed foraging on cranberry bloom. However, it is possible that as a result of their small size, they were underrepresented in visual counts.

Because cranberry growers typically stock their beds with 0.5 to 1.0 honeybee hives per hectare, it is not surprising that honeybee workers and bumble bees were observed at a 2:1 ratio. However, bumble bees were observed collecting pollen 1.4 times as often as honeybees with pollen loads more than twice as large on average. This finding agrees with the earlier report by MacKenzie (1994) that honeybees collect nectar more often than pollen in cranberry. However, for a better estimate of pollinator efficiency, estimates of single-visit pollen deposition are required. Pollen foraging leads to greater fruit set than nectar foraging (Cane and Schiffhauer, 2001), indicating that, despite lower numbers, pollen foragers may provide more pollination services to cranberry than their nectar foraging counterparts. Thus, in the Oregon cranberrygrowing region, bumble bees are likely to be more effective pollinators than honeybees.

Climatic conditions on the southern Oregon coast may be another factor that influences pollinator performance. In the current study, bumble bees largely foraged between 18.3 and $22.2{ }^{\circ} \mathrm{C}$, which corresponds with the observed average daytime temperature in cranberrygrowing regions in Oregon. In contrast, half of the observed honeybees foraged between 21.1 and $26.7{ }^{\circ} \mathrm{C}$ and over $75 \%$ were seen foraging above the average observed temperature $\left(19.5^{\circ} \mathrm{C}\right)$. Although honeybee sightings did increase with wind speed, this is probably because they were grounded at wind speeds above $20 \mathrm{~m} \cdot \mathrm{s}^{-1}$ and were observed crawling through the mat of cranberries, whereas bumble bees were still able to fly. The dominant bee, $B$. vosnesenskii, was observed flying from cranberry flower to cranberry flower at wind speeds above $24 \mathrm{~m} \cdot \mathrm{s}^{-1}$.

Based on their abundance in traps and on flowers, and the size and composition of their pollen loads, bumble bees in general, and $B$. vosnesenskii in particular, are likely to play a significant role in cranberry pollination in Oregon. Bumble bees have previously been found to be excellent pollinators of cranberries in other regions such as the Midwest (Cane and Schiffhauer, 2003; MacKenzie et al., 1995), and their importance is underscored in this study. With the current abundance of native bumble bees in Oregon, growers may be able to reduce their dependence on honeybees for pollination and thereby grow the crop more economically. However, native bumble bee populations vary from year to year and are likely to be affected by surrounding land use changes. Although crop producers in other

Table 2. Multivariate logistic model associating honeybee and bumble bee foraging to abiotic factors. ${ }^{\mathrm{z}}$

\begin{tabular}{lccrc}
\hline & Estimate & SE & z Value & $\operatorname{Pr}(>|z|)$ \\
\hline (Intercept) & 13.95380 & 2.09046 & 6.675 & $2.47 \times 10^{-11 * * *}$ \\
Temperature $(\mathrm{C})$ & -0.19385 & 0.02830 & -6.849 & $7.46 \times 10^{-12 * * *}$ \\
Wind speed $\left(\mathrm{m} \cdot \mathrm{s}^{-1}\right)$ & -0.41137 & 0.09917 & -4.148 & $3.35 \times 10^{-5 * * *}$ \\
\hline
\end{tabular}

${ }^{2}$ Residual deviance is 301.07 on 297 df. Akaike's Information Criterion is 307.07.

$* * * P>0.001$
U.S. states can augment wild populations with commercially reared Bombus impatiens Cresson, legislation prevents the exotic bee from being introduced into the state (State of Oregon, 2011). Hence, Oregon cranberry growers have to depend on native populations for pollination. If wild bumble bees are to be relied on for pollination services, it is critical that conservation efforts are developed to maintain and improve existing populations.

\section{Literature Cited}

BC Cranberry Growers Association. 2007. Industry. 14 Mar. 2011. < http://www.bccranberrygrowers. com/industry/ $>$.

Buchmann, S.L. 1983. Buzz pollination in angiosperms, p. 73-113. In: Jones, C.E. and J.R. Little (ed.). Handbook of experimental pollination biology. Van Nostrand Reinhold, New York, NY.

Burrill, R.M. and A. Dietz. 1981. The response of honey bees to variations in solar radiation and temperature. Apidologie (Celle) 12:319-328.

Cane, J.H. and D. Schiffhauer. 2001. Pollinator genetics and pollination: Do honey bee colonies selected for pollen-hoarding field better pollinators of cranberry Vacciniurn macrocarpon? Ecol. Entomol. 26:117-123.

Cane, J.H. and D. Schiffhauer. 2003. Dose-response relationships between pollination and fruiting refine pollinator comparisons for cranberry [ $\mathrm{Vac}$ cinium macrocarpon (Ericaceae)]. Amer. J. Bot. 90:1425-1432.

Cane, J.H., D. Schiffhauer, and L.J. Kervin. 1996. Pollination, foraging, and nesting ecology of the leaf-cutting bee Megachile (Delomegachile) addenda (Hymenoptera: Megachilidae) on cranberry beds. Ann. Entomol. Soc. Am. 89:361-367.

Eck, P. 1986. Cranberry, p. 109-117. In: Monselise, S.P. (ed.). CRC handbook of fruit set and development. CRC Press, Boca Raton, FL.

Erdtman, G. 1952. Pollen morphology and plant taxonomy: Angiosperms-An introduction to the study of pollen grains and spores. Almqvist \& Wiksell, Stockholm, Sweden.

Evans, E.C. and M. Spivak. 2006. Effects of honey bee (Hymenoptera: Apidae) and bumble bee (Hymenoptera: Apidae) presence on cranberry (Ericales: Ericaceae) pollination. J. Econ. Entomol. 99:614-620.

Filmer, R.S. and C.A. Doehlert. 1959. Use of honeybees in cranberry bogs. Bulletin of the New Jersey Agricultural Experiment Station 588:4.

Free, J.B. 1993. Insect pollination of crops. Academic Press, London, UK.

King, M.J. and S.L. Buchmann. 2003. Floral sonication by bees: Mesosomal vibration by Bombus and Xylocopa, but not Apis (Hymenoptera: Apidae), ejects pollen from poricidal anthers. J. Kans. Entomol. Soc. 76:295-305.

Macfarlane, R.P. 1995. Cranberry pollination and bumble bees. Proc. Wisconsin Cranberry School $6: 1-6$.

Macfarlane, R.P. and K.D. Patten. 1997. Food sources in the management of bumblebee populations around cranberry marshes. Acta Hort. 437:239-244.

Macfarlane, R.P., K.D. Patten, D.F. Meyer, and C.H. Shanks. 1994. Evaluation of commercial bumble bee colonies for cranberry pollination. Melanderia. 50:13-19.

MacKenzie, K.E. 1994. The foraging behaviour of honey bees (Apis mellifera L) and bumble bees (Bombus spp) on cranberry (Vaccinium macrocarpon Ait). Apidologie (Celle) 25:375-383. 
MacKenzie, K.E. and S. Javorek. 1997. The potential of alfalfa leafcutter bees (Megachile rotundata L.) as pollinators of cranberry (Vaccinium macrocarpon Aiton). Acta Hort. 437:345-352.

MacKenzie, K.E., E. Kenna, A.L. Averill, and L. Anne. 1995. Bee (Hymenoptera: Apoidea) diversity and abundance on cranberry in southeastern Massachusetts. Ann. Entomol. Soc. Am. 88:334-341.

Percival, M. 1947. Pollen collection by Apis mellifera. New Phytol. 46:142-173.

R Development Core Team. 2010. R: A language and environment for statistical computing.
Version 2.11.1. R Foundation for Statistical Computing, Vienna, Austria.

Ratti, C.M., H.A. Higo, T.L. Griswold, and M.L. Winston. 2008. Bumble bees influence berry size in commercial Vaccinium spp. cultivation in British Columbia. Can. Entomol. 140:348-363.

Sarracino, J. and N. Vorsa. 1991. Self and cross fertility in cranberry. Euphytica 58:129-136.

State of Oregon. 2011. Oregon approved insect list. ODA Plant Division, Insect Pest Prevention and Management, Salem. 14 Mar. 2011. <http:// www.oregon.gov/ODA/PLANT/IPPM/appr_ insects.shtml>.
Stephen, W. and S. Rao. 2005. Unscented color traps for non-Apis bees. J. Kans. Entomol. Soc. 78:373-380.

Stubbs, C.S. and F.A. Drummond. 1997. Blueberry and cranberry (Vaccinium spp.) pollination: A comparison of managed and native bee foraging behavior. Acta Hort. 437:341-344.

U.S. Department of Agriculture. 2009a. Aug. 18 Oregon cranberries. U.S. Dept. Agr., Washington, DC.

U.S. Department of Agriculture. 2009b. June. Oregon cranberries. U.S. Dept. Agr., Washington, DC. 